\title{
PERBANDINGAN SEGMENTASI CITRA TELUR AYAM MENGGUNAKAN METODE OTSU BERDASARKAN PERBEDAAN RUANG WARNA RGB DAN HSV
}

\author{
Gd Angga Pradipta1', Pt Desiana Wulaning Ayu² \\ 1,2Program Studi Sistem Informasi, STMIK STIKOM BALI \\ Jl.Raya Puputan Renon No.86, Bali \\ Telp (0361) 244445
}

E-mail: angga_pradipta@stikom-bali.ac.id, wulaning.ayu@gmail.com

\begin{abstract}
Abstrak
Segmentasi bertujuan untuk membagi citra ke dalam sejumlah bagian atau objek, objek pada penelitian ini berupa telur ayam yang bertujuan untuk memperoleh garis tepi dari citra telur dan dapat mengidentifikasi bercak kotor pada telur. Metode yang digunakan pada penelitian ini adalah dengan segmentasi berdasarkan perbedaan ruang warna, yaitu ruang warna RGB dan HSV, serta segmentasi dengan menggunakan metode otsu. Hasil yang diperoleh dari 20 sampel telur yang digunakan menunjukkan hasil segmentasi dengan ruang warna RGB dalam mendeteksi garis tepi citra pada telur lebih baik dibandingkan dengan ruang warna HSV, ini terlihat dari pengujian secara visual dimana ruang warna RGB memberikan hasil yang lebih sempurna dalam memisahkan telur dengan objek yang lainnya. Sedangkan dalam pengujian kualitas citra hasil dari segementasi dengan pengujian MSE dan PSNR, ruang warna HSV memberikan hasil yang lebih baik dengan RGB . Penelitian ini diharapkan dapat memberikan kontribusi penggunaan metode ruang warna agar dapat diterapkan pada segmentasi citra.
\end{abstract}

Kata Kunci: Otsu, RGB, HSV, Segmentasi

\begin{abstract}
Segmentation aims to divide the image into a number of parts or objects, objects in this study of chicken eggs which aims to obtain the outline of the image of the egg and can identify the dirty spots on the eggs. To get the purpose of this study, the method used is segmentation based on differences in the color space, ie RGB and HSV color space, as well as segmentation using Otsu method. Results obtained from 20 samples of eggs used shows segmentation results with the RGB color space to detect the outline of the image on the eggs better than the HSV color space, is visible from the testing visually where RGB color space provide a more perfect in separating egg other objects. While the image quality testing results from testing segmentation with MSE and PSNR, the HSV color space provides better results with RGB. This research is expected to contribute the use of methods of color space that can be applied to image
\end{abstract}

Keyword: Otsu, RGB, HSV, Segmentasi

\section{PENDAHULUAN}

Telur ayam merupakan salah satu hasil peternakan yang banyak dikonsumsi oleh masyarakat di Indonesia. Menurut data pada Direktorat jendral peternakan dan kesehatan hewan, jumlah produksi telur ayam ras petelur pada tahun 2016 mencapai 1.428.195 butir telur di seluruh provinsi dan Bali menduduki peringkat kedelapan dengan jumlah total produksi telur 41.352 butir telur.
Ini menunjukkan industri peternakan ayam petelur masih tinggi di provinsi Bali dan membutuhkan dukungan yang salah satunya adalah pengelompokan kualitas telur yang berpengaruh pada harga jualnya. Berat dan juga volume dari telur ayam tersebut menjadi pengaruh dari komposisi bahan baku. Maka dari itu diperlukan standarisasi dalam klasifikasi ukuran dan bobot telur ayam yang akan dipakai dalam 
proses industri. Berdasarkan Badan Standardisasi Nasional (BSN) dengan no SNI 3926:2008, ruang lingkup standar menetapkan salah satu parameter untuk telur konsumsi adalah ukuran bobot dan diameter telur. Pengawasan mutu telur ayam ras dapat dilakukan terhadap keadaan fisik, kesegaran isi telur, pemeriksaan kerusakan dan pengukuran komposisi fisik telur. Keadaan fisik dari telur mencakup hal ukuran (berat, panjang dan lebar), warna, kondisi kulit telur,rupa (bulat dan lonjong) dan kebersihan kerabang (kulit) telur ayam ras.

Untuk bisa mendapatkan klasifikasi lingkar telur ayam tersebut salah satu cara yang dapat dilakukan pada pengolahan citra adalah dengan melakukan segmentasi citra terlebih dahulu. Dari hasil segmentasi tersebut akan berlanjut untuk bisa mendapatkan diameter dari telur. Penentuan ruang warna dan kecocokan metode yang digunakan dalam segmentasi akan sangat berpengaruh pada tahap pengolah citra berikutnya yaitu pencarian diameter telur.

Salah satu bagian dari image processing pada sebuah citra adalah segmentasi. Segmentasi sendiri bertujuan untuk membagi sebuah citra ke dalam sejumlah bagian atau obyek. Atau segmentasi dapat bertujuan untuk proses pemisahan sebuah object dari background, sehinga obyek tersebut dapat diproses untuk keperluan yang lain (Jian \& Xiaowei, 2012). Secara umum proses segmentasi dapat terbagi menjadi 3 bagian yaitu berdasarkan klasifikasi (classification based segmentation),berdasarkan tepi (edge based) dan berdasarkan daerah (region based segmentation).

Segmentasi berdasarkan klasifikasi adalah proses segmentasi yang dilakukan dengan mencari kesamaan ukuran dari pada pixel. Segmentasi berdasarkan tepi adalah proses segmentasi untuk mendapatkan garis yang ada pada gambar dengan anggapan bahwa garis tersebut merupakan tepi dari obyek yang memisahkan obyek satu dengan obyek yang lain atau antara obyek dengan background. Sedangkan segmentasi berdasarkan daerah daerah yang diyakini merupakan sebuah obyek. Untuk mendapatkan daerah tersebut, dilakukan analisa terhadap kesamaan tekstur, warna pada pixel yang terdapat pada gambar (Pan et al., 2016).

Sedangkan pada peneltian ini akan melakukan proses segmentasi berdasarkan deteksi tepi (edge detection) dengan obyek telur ayam. Proses deteksi tepi obyek akan menggunakan metode prewitt sehingga didapatkan garis tepi yang dianggap pinggir telur ayam. Tujuan dari segmentasi deteksi tepi dari telur ayam kedepannya bertujuan untuk membantu proses dalam mencari ukuran diameter dan bobot dari suatu telur agar lebih akurat dan untuk mengetahui perbandingan kinerja dari kedua ruang warna. Sebelum dilakukannya proses segmentasi dengan deteksi tepi menggunakan metode prewitt, masingmasing citra telur ayam akan dilakukan proses preprocessing citra dengan mengubah nya dalam 2 koordinat ruang warna, yaitu ruang warna CIELAB dan ruang warna RGB. RGB (Red, Green, Blue ) menampilkan citra dalam 3 komponen warna yaitu merah, hijau dan biru, disebut juga sebagai "additive primaries" karena warna citra pada ruang warna RGB didapat dari kombinasi dari ketiga komponen warna (Lin \& Lin, 2016) . CIELAB lebih dikenal dengan ruang warna $\mathrm{CIEL}^{*} \mathrm{a}^{*} \mathrm{~b}$ dimana $\mathrm{L}$ didefinisikan sebagai lightness, Ditetapkan oleh Komisi Internationale de l'Eclairage $(\mathrm{CIE})$, ruang warna $\mathrm{L}^{*} \mathrm{a}^{*} \mathrm{~b}^{*}$ dimodelkan setelah teori warna lainnya yang menyatakan bahwa dua warna tidak bisa merah dan hijau pada waktu yang sama atau kuning dan biru pada saat yang sama waktu. Seperti ditunjukkan di bawah, $L^{*}$ menunjukkan Light atau terang, $\mathrm{a}^{*}$ adalah koordinat merah / hijau, dan $b^{*}$ adalah koordinat kuning atau biru (Narkhede \& Gokhale, 2015).

\section{TINJAUAN PUSTAKA}

Beberapa penelitian yang berkaitan dengan penelitian dengan objek telur ayam, diantaranya adalah penelitian yang berjudul Automatic Identification of Defects on Eggshell Through a Multispectral Vision System (Lorendana, 2012) Penelitian ini berfokus pada identifikasi bercak atau noda pada telur ayam yang berwarna coklat (dirty eggshell) yang disebabkan oleh darah, bulu, kotoran (feces) dengan menggunakan pendekatan algoritma klasifikasi untuk 
membedakan bercak dari 236 butir yang teridentifikasi kotor (dirty eggshell). Proses klasifikasi berdasarkan algoritma yang digunakan mendekati kebenaran sebesar $98 \%$ yang hanya membutuhkan waktu prosesnya sebesar 0.05 detik. Penelitian selanjutnya dengan judul Color index analysis for automatic detection of eggshell defects (Maria, 2012) , penelitian di fokuskan untuk mendeteksi secara otomatis cacat pada telur secara real time dengan menggunakan analisis index warna (color index) pada 50 telur ayam yang telah di sortir sebagai sampel. Pada penelitian yang berjudul Deteksi Tepi Citra Telur dengan Algoritma Prewitt untuk Perhitungan Volume (Huda, 2016), melakukan pencarian terhadap deteksi tepi pada citra telur dan perhitungan volume telur, dimana pencariaan keakuratan dilakukan dengan membandingkan pencarian manual hasil ukur dengan gelas ukur) dan perhitungan berdasarkan edge detection.

\section{METODOLOGI PENELITIAN}

Beberapa metodelogi penelitian yang dilakukan dalam penelitian ini pertama adalah pengumpulan data uji atau sampel telur ayam. 20 sampel telur ayam difoto dengan jarak $20 \mathrm{~cm}$ tegak lurus dari posisi telur. Hal ini bertujuan untuk agar menyamakan kualitas dan hasil foto dari setiap data uji. Tahapan Diagram Alir Penelitian ditunjukkan pada dijelaskan pada Gambar 1.

Preprocessing citra adalah dengan menyeragamkan seluruh citra uji telur ayam pada dimensi piksel sebesar $273 \times 240$ piksel.

Kemudian masing-masing citra uji dilakukan pemisahan ke dalam ruang warna, yaitu RGB dan HSV. Untuk transformasi dari RGB ke HSV, diasumsikan koordinatkoordinat $R, G, B \quad[0,1]$ adalah berurutan merah,hijau,biru dalam ruang warna RGB, dengan max adalah nilai maksimum dari nilai red, green, blue, dan min adalah nilai minimum dari nilai red, green, blue.

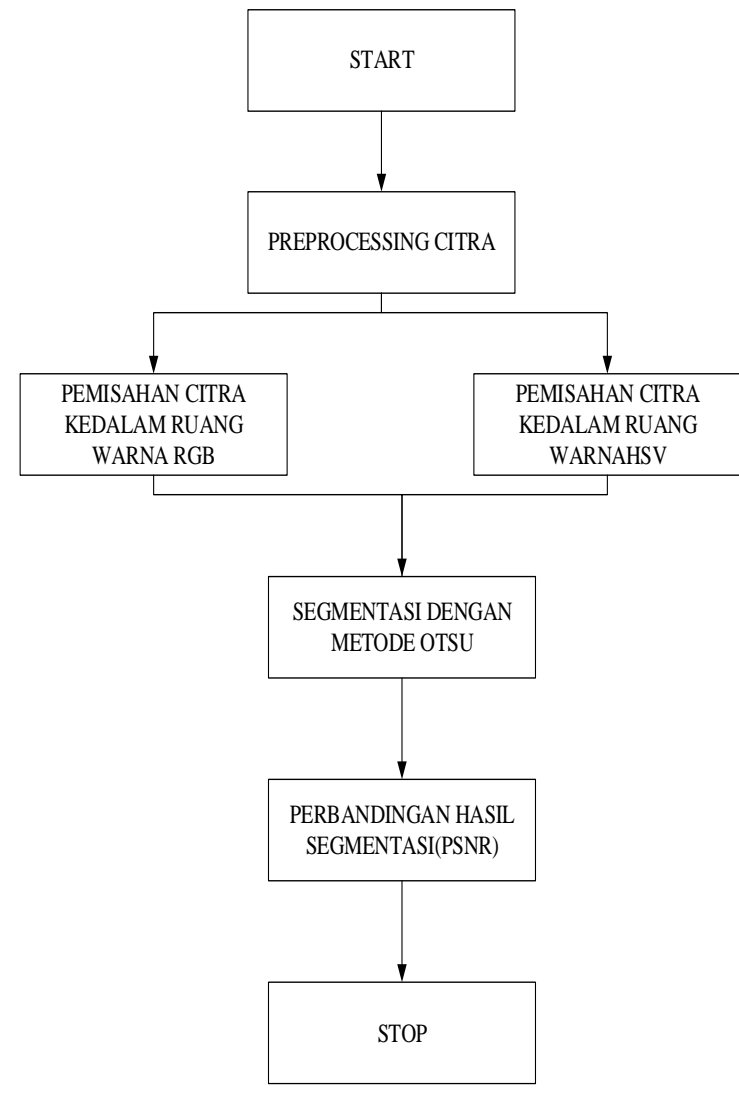

Gambar 1. Diagram alir penelitian

Untuk memperoleh sudut hue $[0,360]$ yang tepat untuk ruang warna HSV, menggunakan rumus berikut.

$$
h(\text { hue })=\left\{\begin{array}{c}
0, \quad \text { jika } \max =\min \\
60^{\circ} \times\left(\frac{G-B}{\max -\min } \bmod 6\right), \text { jika } \max =R \\
60^{\circ} \times\left(\frac{B-R}{\max -\min }+2\right), \text { jika } \max =G \\
60^{\circ} \times\left(\frac{R-G}{\max -\min }+4\right), \quad \text { jika } \max =B
\end{array}\right.
$$

Nilai-nilai untuk $s$ dan $v$ pada HSV didefinisikan sebagai berikut :

$$
\begin{gathered}
s(\text { saturation })=\left\{\begin{array}{l}
0, \text { jika } \max =\min \\
\frac{\max -\min }{V}, \text { otherwise }
\end{array}\right. \\
V(\text { value })=\max
\end{gathered}
$$

Rumus di atas menghasilkan nilai value dan saturation dalam jangkuan RGB $[0,1]$. Pengalian terlebih dahulu dilakukan 
dengan 255 untuk memperoleh nilai dengan jangkauan RGB $[0,255]$. Sebagai contoh penerapan transformasi RGB $(65,27,234)$ ke dalam bentuk HSV, langkah pertama diubah dalam jangkauan $[0,1]$ dengan membagi setiap nilai dengan 255:

$$
\left(\frac{65}{255}, \frac{27}{255}, \frac{234}{255}\right)=(0.255,0.16,0.918)
$$

RGB $(0.255,0.106,0.918)$ ini yang akan ditransformasikan ke dalam bentuk HSV.

$$
\begin{aligned}
& \text { Max = nilai } \mathrm{B} \text { (blue) }=0.918 \text {, } \\
& \text { Min } \quad \text { nilai } \mathrm{G} \text { (green) }=0.106 \text {, } \\
& \text { Max-min } \quad=0.918-0.106=0.812 \text {. } \\
& \mathbf{H}(\text { Hue })=60^{\circ} \times\left(\frac{R-G}{M A X-M I I N}+4\right) \text {, karena Max } \\
& \text { adalah } \mathrm{B}(\text { Blue }) \text {. } \\
& =60^{0} \times\left(\frac{0.255-0.106}{0.812}+4\right)=251 \\
& \mathrm{~V}(\text { value }) \quad=\max =0.918 \\
& \mathrm{~S}(\text { saturation })=\frac{\text { Max }- \text { Min }}{v} \text {, } \\
& \text { karena } \max <>\min \\
& =\frac{0.812}{0.918}=0.885
\end{aligned}
$$

Sehingga nilai RGB $(65,27,234)$ di transformasikan menjadi HSV $(251,0.885,0.918)$ dengan jangkauan $[0,1]$.

Masing-masing citra yang telah diubah ke dalam ruang warna, akan dilakukan proses segmentasi untuk menentukan garis tepi pada telur dan noda/bercak yang terdapat pada telur. Segmentasi yang digunakan adalah dengan metode Otsu. Pendekatan yang dilakukan oleh metode otsu adalah dengan melakukan analisis diskriminan yaitu menentukan suatu variable yang dapat membedakan antara dua atau lebih kelompok yang muncul secara alami. Analisis diskriminan akan memaksimumkan variable tersebut agar dapat membagi objek latardepan (foreground) dan latar belakang (background). Nilai ambang akan dicari dari suatu citra gray level dinyatakan dengan $k$. Nilai $k$ berkisar antara 1 sampai dengan $L$, dengan nilai $L=255$. Probabilitas setiap pixel pada level ke i dapat dinyatakan:

$$
P_{i}=n_{i} / \mathrm{N}
$$

Dengan : $n_{i}$ menyatakan jumlah pixel pada level ke $i$. $\mathrm{N}$ menyatakan total jumlah pixel pada citra.

Nilai Zeroth cumulative moment, First cumulative moment, dan total nilai mean berturut-turut dapat dinyatakan dengan rumus berikut:

$$
\begin{aligned}
& (i)(k)=\sum_{i=1}^{k} P i \\
& \mu(k)=\sum_{i=1}^{k} i . P i \\
& \mu(r)=\sum_{i=1}^{k} i . P i
\end{aligned}
$$

Nilai ambang $\mathrm{k}$ dapat ditentukan dengan memaksimumkan persamaan:

$$
\sigma_{B}^{2}\left(k^{*}\right)=\max _{1 \leq k<L} \sigma_{B}^{2}(k)
$$

Pengujian hasil segmentasi dengan menggunakan metode MSE dan PSNR.

Nilai MSE didapatkan melalui:

$$
\begin{aligned}
M S E & =\frac{1}{m n} \sum_{i=0}^{m-1} \sum_{j=0}^{n-1}[I(i, j)-K(i, j)]^{2} \\
\text { PSNR } & =10 \cdot \log _{10}\left(\frac{M A X_{I}^{2}}{M S E}\right) \\
& =20 \cdot \log _{10}\left(\frac{M A X_{I}}{\sqrt{M S E}}\right) \\
& =20 \cdot \log _{10}\left(M A X_{I}\right)-10 \cdot \log _{10}(M S E)
\end{aligned}
$$

\section{HASIL DAN PEMBAHASAN}

Hasil dari penelitian ini berupa desain sistem, implementasi sistem, hasil pengujian sistem serta analisis hasil.

\section{DESAIN DAN IMPLEMENTASI SISTEM}

Desain sistem dirancang dan dibuat untuk mempermudah melihat hasil uji dari citra yang diuji, dibuat dalam bentuk GUI (Graphic User Interface) MATLAB. GUI yang dimaksud ditujukkan pada gambar 2 .

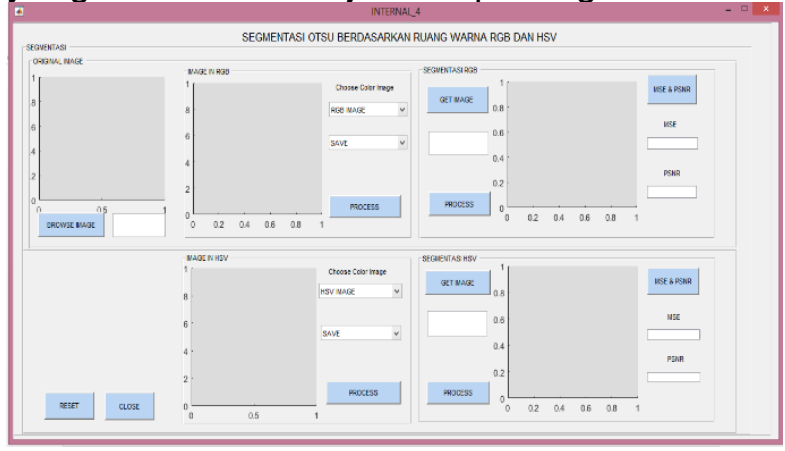

Gambar 2. Desain sistem pada matlab 
Desain sistem atau interface rancangan ini digunakan untuk mendapatkan perbedaan konversi antara ruang warna RGB dan HSV serta hasil segmentasi dengan metode otsu berdasarkan perbedaan ruang warna. Sedangkan MSE dan PSNR digunakan untuk melihat nilai hasil pengujian pada proses segmentasi.

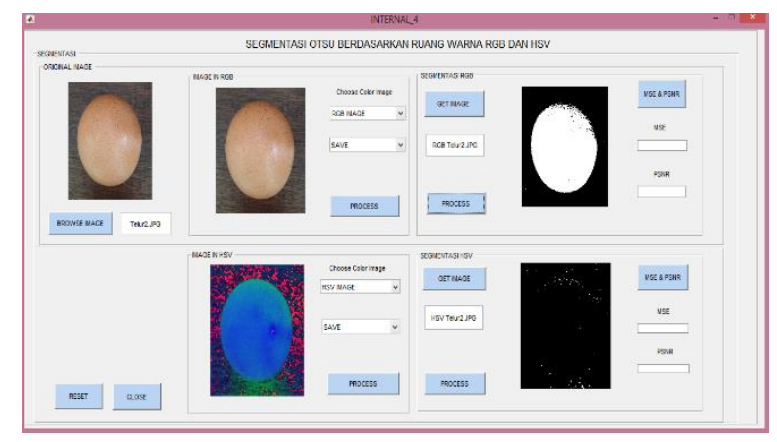

Gambar 3. Implementasi sistem
Pada tahap implementasi sistem, sampai saat ini sudah selesai dilakukan dan dikerjakan, interface yang dirancang sudah dapat menghasilkan perbandingan segmentasai antar ruang warna, RGB dan HSV

Hasil uji dari sitem yang telah diimplementasikan, berupa perbandingan hasil segmentasi antara kedua ruang warna. Dari 20 sampel telur yang telah dilakukan pengujian, didapatkan hasil segmentasi yang dapat dilihat pada daftar rujukan dibawah.

Untuk mengetahui perbandingan hasil dari kedua ruang warna terhadap segmentasi, maka disajikan dalam tabel checklist pada tabel 2.

Tabel 2. Checklist keberhasilan deteksi lingkar telur dan dirty egg pada kedua metode (RGB dan HSV)

\begin{tabular}{lcccc}
\hline $\begin{array}{l}\text { Nama Citra RGB (Deteksi Lingkar } \\
\text { Telur) }\end{array}$ & $\begin{array}{c}\text { HSV (Deteksi } \\
\text { Lingkar Telur) }\end{array}$ & $\begin{array}{c}\text { RGB(Deteksi } \\
\text { Dirty/Clean Eggs) }\end{array}$ & $\begin{array}{c}\text { HSV(Deteksi } \\
\text { Dirty/Clean } \\
\text { Eggs) }\end{array}$ \\
\hline Telur 1.jpg & $\checkmark$ & $\checkmark$ & $\checkmark$ & - \\
Telur 2.jpg & $\checkmark$ & - & - & - \\
Telur 3.jpg & $\checkmark$ & - & - & - \\
Telur 4.jpg & $\checkmark$ & - & - & - \\
Telur 5.jpg & $\checkmark$ & - & - & - \\
Telur 6.jpg & $\checkmark$ & - & - & - \\
Telur 7.jpg & - & $\checkmark$ & $\checkmark$ & - \\
Telur 8.jpg & $\checkmark$ & - & $\checkmark$ & - \\
Telur 9.jpg & $\checkmark$ & - & - & - \\
Telur 10.jpg & - & - & - & - \\
Telur 11.jpg & - & - & - & - \\
Telur 12.jpg & - & - & $\checkmark$ & - \\
Telur 13.jpg & - & $\checkmark$ & $\checkmark$ & - \\
Telur 14.jpg & $\checkmark$ & - & - & - \\
Telur 15.jpg & - & - & - & - \\
Telur 16.jpg & - & - & $\checkmark$ & - \\
Telur 17.jpg & $\checkmark$ & - & $\checkmark$ & - \\
Telur 18.jpg & $\checkmark$ & - & $\checkmark$ & - \\
Telur 19.jpg & $\checkmark$ & - & & - \\
Telur 20.jpg & $\checkmark$ & - & & - \\
\hline
\end{tabular}

Note : $\sqrt{ }$ : berhasil

\section{: tidak berhasil}

Dari tabel 2, diperoleh hasil perbandingan segmentasi untuk deteksi lingkar telur dan dirty eggs. Untuk memudahkan dalam melihat hasil perbandingannya, maka dituangkan dalam bentuk grafik seperti yang terlihat pada grafik 1 dan grafik 2. Masing-masing hasil segmentasi yang berhasil dalam mendeteksi lingkar telur diberikan bobot nilai 10 dan nilai bobot yang tidak berhasil mendeteksi lingkar 
telur di berikan nilai 1, hal ini bertujuan untuk memudahkan melihat perbandingan hasil kedua ruang warna terlihat pada gambar 4 .

\section{Perbandingan Segmentasi \\ Untuk Deteksi Lingkar Telur}

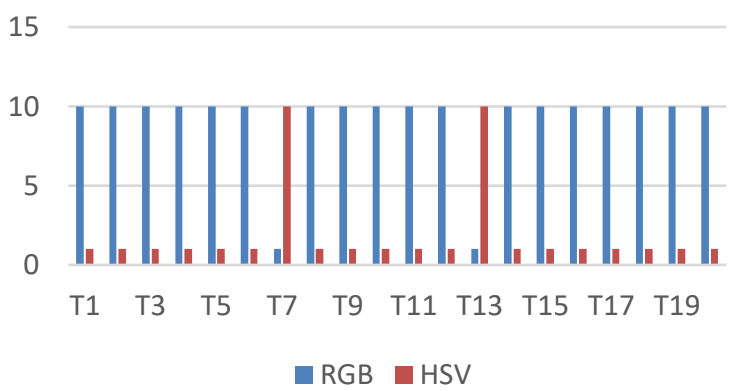

Gambar 4. Hasil perbandingan segmentasi untuk deteksi lingkar telur

Dari gambar 4, terlihat hasil segmentasi dengan metode otsu pada ruang warna RGB memberikan hasil yang lebih baik dibandingkan dengan ruang warna HSV. Dari 20 sampel telur, 18 Telur berhasil terdeteksi untuk lingkar telur, sedangkan 2 HSV. Sedangkan pada ruang warna HSV hanya 2 citra yang dapat mendeteksi lingkar telur, sedangkan 18 citra tidak berhasil. Dari hasil pengujian dan analisa, ruang warna RGB menunjukkan hasil yang lebih baik dalam mendeteksi lingkar telur.

\section{Perbandingan Segmentasi Untuk Deteksi Dirty Egg}

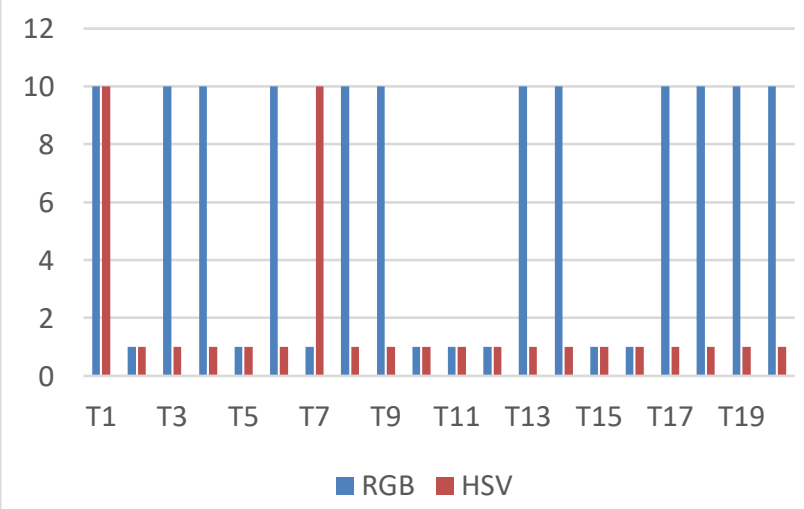

Gambar 5. Hasil perbandingan segmentasi untuk dirty atau clean egg
Dari gambar 5, terlihat hasil segmentasi dengan metode otsu pada ruang warna RGB memberikan hasil yang lebih baik dibandingkan dengan ruang warna HSV. Dari 20 sampel telur, 12 Telur berhasil terdeteksi untuk membedakan dirty atau clean egg. Sedangkan pada ruang warna HSV hanya 2 citra yang dapat mendeteksi clean atau dirty egg. Dari hasil tersebut, ruang warna RGB menunjukkan hasil yang lebih baik dalam mendeteksi kotor atau kebersihan telur.

Analisa Penilaian Kualitas Citra Berdasarkan Hasil MSE dan PSNR Pengujian kualitas citra dilakukan secara objektif dengan pengujian MSE (Mean Square Error) dan PSNR, hasil citra segmentasi akan disisipi gausian noise dengan nilai piksel yang sama, kemudian dari hasil rekontruksi masing-masing dari citra akan menghasilkan nilai MSE dan PSNR, yang dapat menunjukkan hasil kualitas citra. Semakin tinggi nilai PSNR dalam citra, maka menunjukkan kualitas citra yang lebih baik. Tabel 5.3 menunjukkan hasil pengujian untuk nilai MSE dan PSNR pada masing-masing citra hasil segmentasi.

Tabel 3. Hasil Pengujian MSE dan PSNR

\begin{tabular}{lcccc}
\hline $\begin{array}{l}\text { Data } \\
\text { Telur }\end{array}$ & $\begin{array}{c}\text { MSE } \\
(\mathrm{RGB})\end{array}$ & $\begin{array}{c}\text { MSE } \\
(\mathrm{HSV})\end{array}$ & $\begin{array}{c}\text { PNSR } \\
(\mathrm{RGB})\end{array}$ & $\begin{array}{c}\text { PSNR } \\
(\mathrm{HSV})\end{array}$ \\
\hline Telur 1 & 3244,01 & 3243,67 & 13,0323 & 13,167 \\
Telur 2 & 3245,59 & 3243,29 & 13,0519 & 13,0541 \\
Telur 3 & 3234,9 & 3233,87 & 13,4562 & 13,506 \\
Telur 4 & 3344,46 & 3344,12 & 13,1344 & 13,1675 \\
Telur 5 & 3208,97 & 3238,47 & 13,1011 & 13,0614 \\
Telur 6 & 3223,54 & 3224,43 & 13,2122 & 13,5788 \\
Telur 7 & 3246,33 & 3247,7 & 13,0509 & 13,049 \\
Telur 8 & 3244,86 & 3216,35 & 13,0528 & 13,0912 \\
Telur 9 & 3256,11 & 3248,33 & 13,0378 & 13,0482 \\
Telur 10 & $32,17,52$ & 3241,71 & 13,0896 & 13,0571 \\
Telur 11 & 3253,45 & 3244,98 & 13,0414 & 13,0527 \\
Telur 12 & 3246,07 & 3244,61 & 13,0512 & 13,0532 \\
Telur 13 & 3241,57 & 3236,45 & 13,0572 & 13,0641 \\
Telur 14 & 3238,91 & 3241,48 & 13,0608 & 13,0569 \\
Telur 15 & 3248,91 & 325796 & 13,483 & 13,0353 \\
Telur 16 & 3237,57 & 3231,43 & 13,0626 & 13,0709 \\
Telur 17 & 3233,12 & 3239,48 & 13,0686 & 13,0594 \\
Telur 18 & 3247,47 & 3245,18 & 13,0377 & 13,0524 \\
Telur 19 & 3256,2 & 3239,48 & 13,0377 & 13,6 \\
Telur 20 & 3237,18 & 3234,93 & 13,0631 & 13,0662 \\
\hline
\end{tabular}




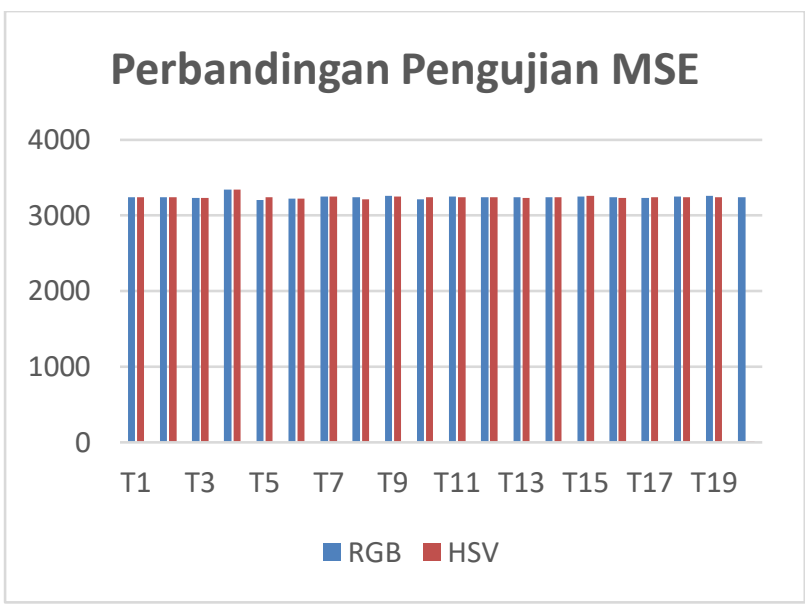

\section{Perbandingan Pengujian PSNR}

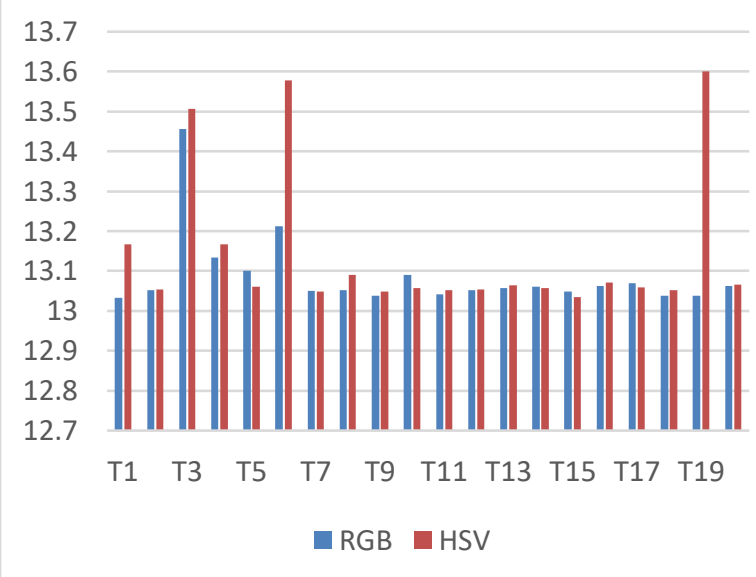

Gambar 6. Perbandingan hasil MSE \& PSNR ruang warna RGB dan HSV

Gambar 6 menunjukkan hasil MSE dengan rung warna HSV, memiliki persentase yang lebih rendah dibandingkan dengan RGB, dari 20 citra uji, 20 citra menunjukkan nilai ruang warna HSV memiliki nilai MSE lebih rendah dari ruang warna RGB, yang artinya segmentasi dengan ruang warna HSV setelah disispi gausian noise, memiliki nilai HSV yang lebih rendah, hal ini mengindikasikan hasil segmentasi dengan ruang warna HSV menunjukkan hasil kualitas citra yang lebih baik dari ruang warna RGB. Sedangkan untuk nilai distorsi rata-rata di bawah $30 \mathrm{~dB}$, yang mengindikasikan kualitas yang relative rendah, dimana distorsi yang dikarenakan penyisipan terlihat jelas. Sedangkan untuk PSNR nilai citra HSV memiliki hasil yang lebih tinggi dimana sesuai dengan teori mengindikasikan kualiatas citra yang lebih baik.

\section{SIMPULAN DAN SARAN}

Dari penelitian yang telah dilakukan menunjukkan unjuk kerja dari metode ruang warna RGB menghasilkan citra segmentasi untuk mendeteksi lingkar telur yang lebih baik, secara visual ditunjukkan dengan keberhasilan dalam mendeteksi lingkar telur yang lebih akurat sebanyak 18 citra sedangkan ruang warna HSV hanya dapat mendeteksi sebanyak 2 citra, sedangkan untuk mendeteksi bercak/ dirty eggs, ruang warna RGB dapat mendeteksi sebanyak 12 citra dan 8 gagal mendeteksi dan ruang warna HSV sebanyak 2 citra terdeteksi dan 18 tidak terdeteksi.

Hasil pada pengujian PSNR \& MSE menunjukkan hasil yang berbeda. Kualiatas citra setelah dilakukan segmentasi dengan metode otsu menunjukkan bahwa ruang warna HSV memiliki kualitas yang lebih baik ketimbang RGB. Ini dibuktikan dengan pengujina yang dilakukan dengan hasil nila PSNR dari ruang HSV lebih tinggi $100 \%$ dari RGB dan nilai MSE ruang HSV lebih rendah $100 \%$ dari RGB.

\section{DAFTAR PUSTAKA}

Huda, M. (2016). DETEKSI TEPI CITRA TELUR DENGAN ALGORITMA PREWITT UNTUK PERHITUNGAN VOLUME. Prosiding Seminar Nasional IPTEK Terapan (SENIT) 2016 Pengembangan Sumber Daya Lokal Berbasis IPTEK, 1(1).

Jian, Z., \& Xiaowei, C. (2012). Nonsubsampled contourlets based Synthetic Aperture Radar images segmentation. In Engineering Design and Manufacturing Informatization 2012 3rd International Conference on System Science (Vol. 2, pp. 216218).

Lin, P. T., \& Lin, B. R. (2016). Fuzzy automatic contrast enhancement based on fuzzy C-means clustering in CIELAB color space. In 2016 12th IEEE/ASME Conference on Mechatronic and Embedded Systems and 
Applications (MESA) (pp. 1-10). https://doi.org/10.1109/MESA.2016. 7587156

Lorendana, L. (2012). Automatic Identification of defect on Eggshell Through a Multispectral Vision System. Food Bioprocess Technology. https://doi.org/DOI 10.1007/s11947-011-0672-x.

Narkhede, P. R., \& Gokhale, A. V. (2015). Color particle filter based object tracking using frame segmentation in CIELab* and HSV color spaces. In 2015 International Conference on Communications and Signal Processing (ICCSP) (pp. 0804-
0808).

https://doi.org/10.1109/ICCSP.2015 7322604

Pan, J., Zheng, X. W., Sun, L., Yang, L. N., Wang, Y. L., Luo, H. W., \& Wang, P. S. P. (2016). Image segmentation based on 2D OTSU and simplified swarm optimization. In 2016 International Conference on Machine Learning and Cybernetics (ICMLC) (Vol. 2, pp. 1026-1030). https://doi.org/10.1109/ICMLC.2016. 7873020

Maria, C. 2012. Color Index Analysis for Automatic detection of Eggshell Defect. SPIE.

\section{DAFTAR RUJUKAN}

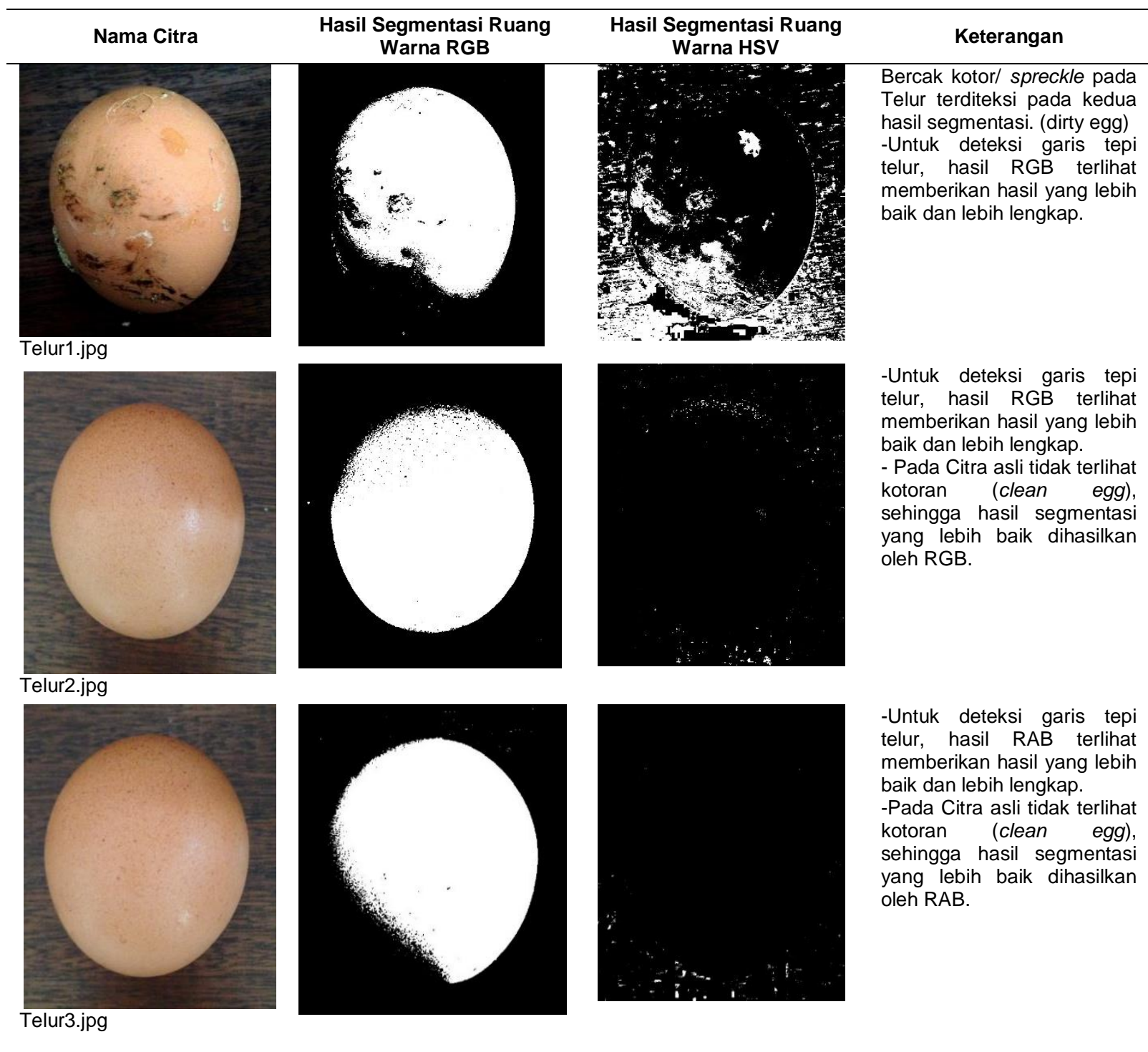




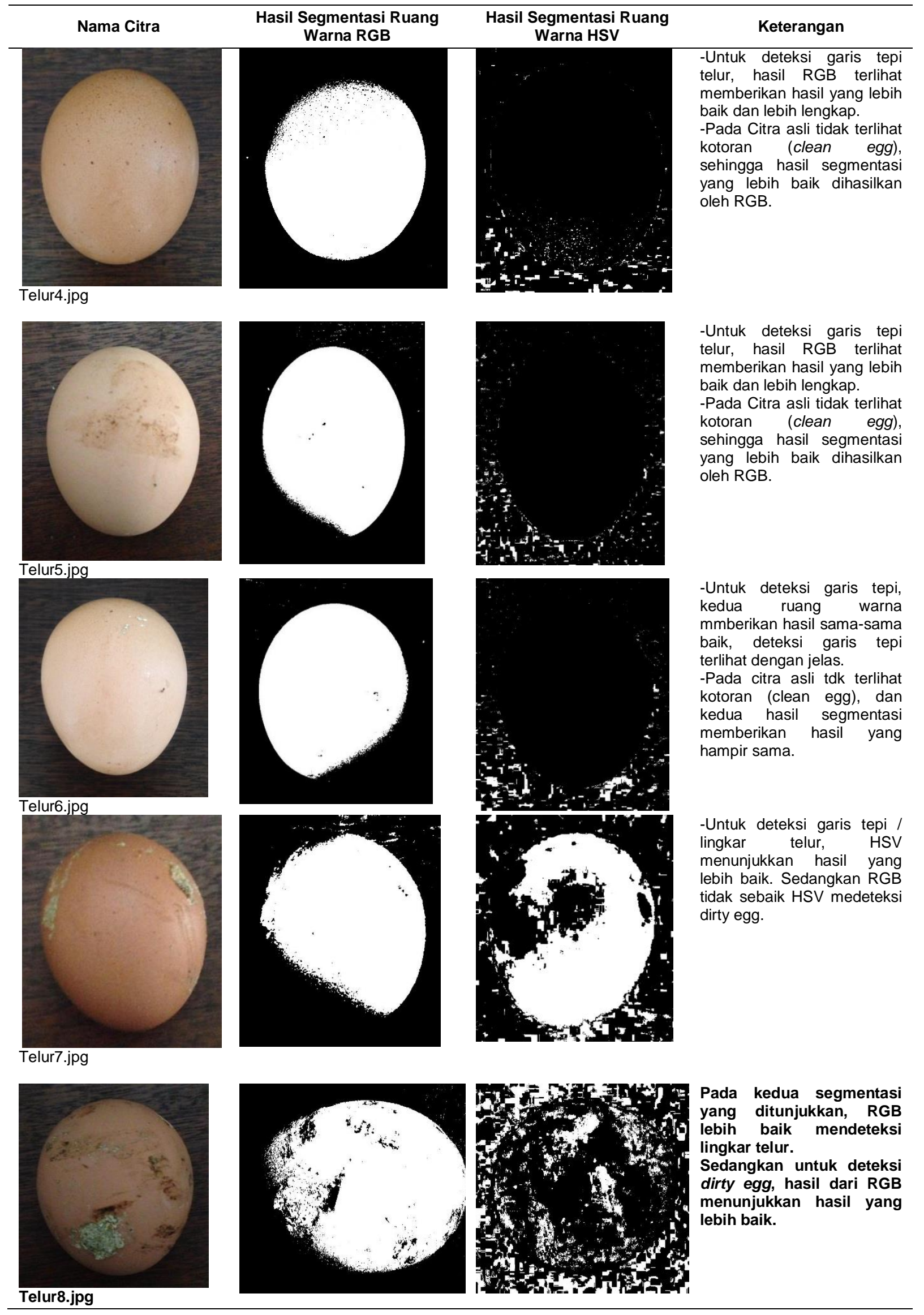




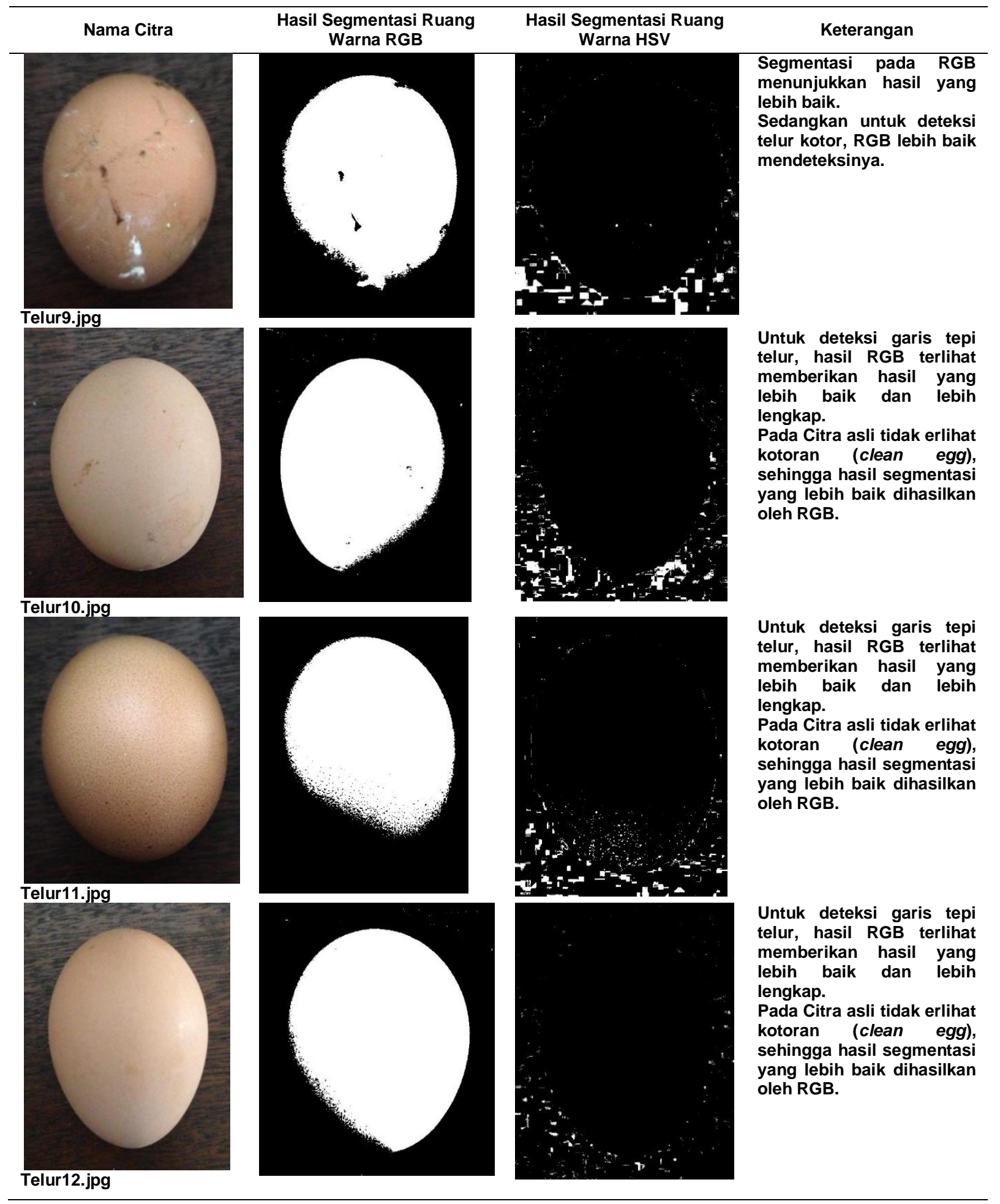




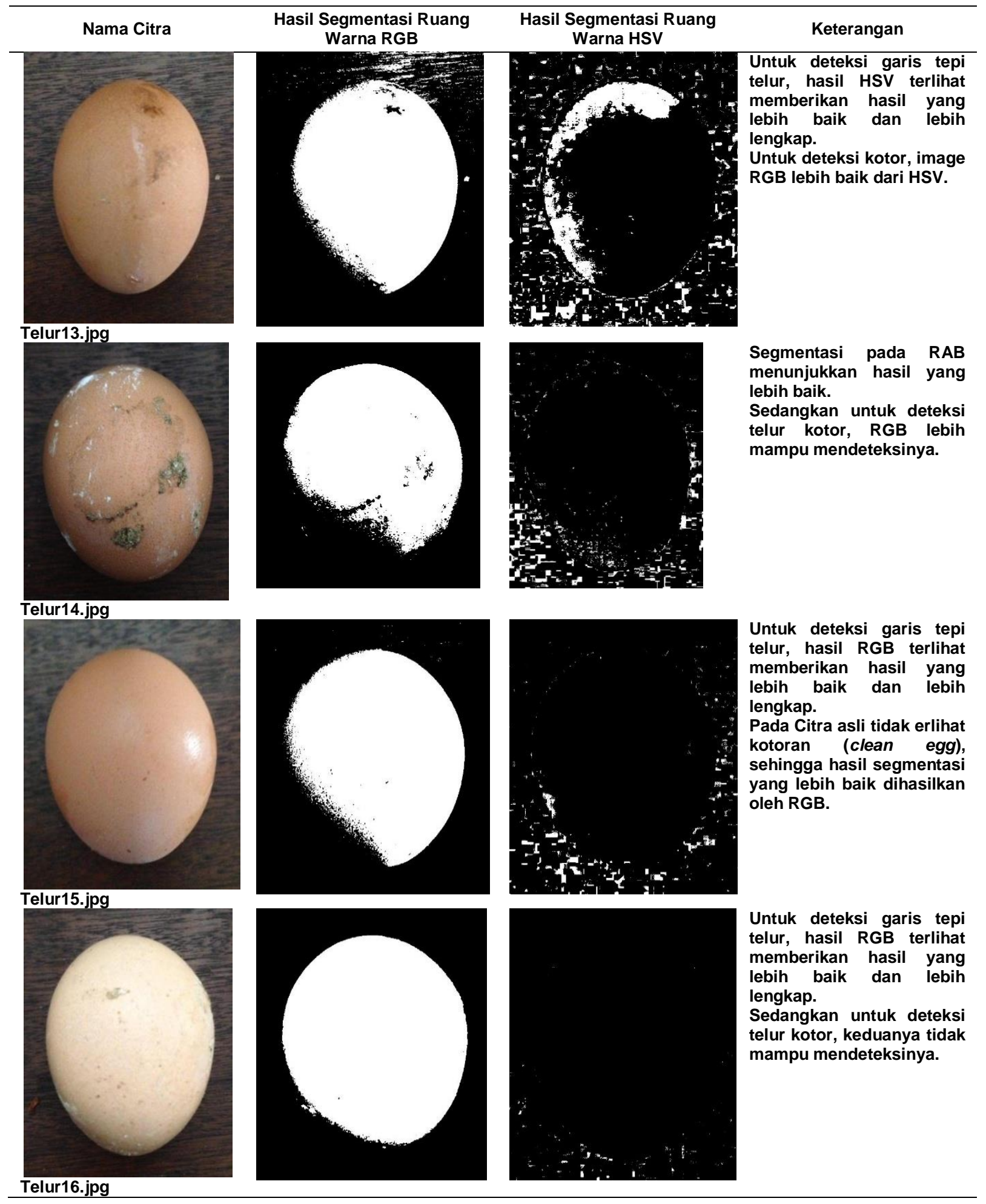




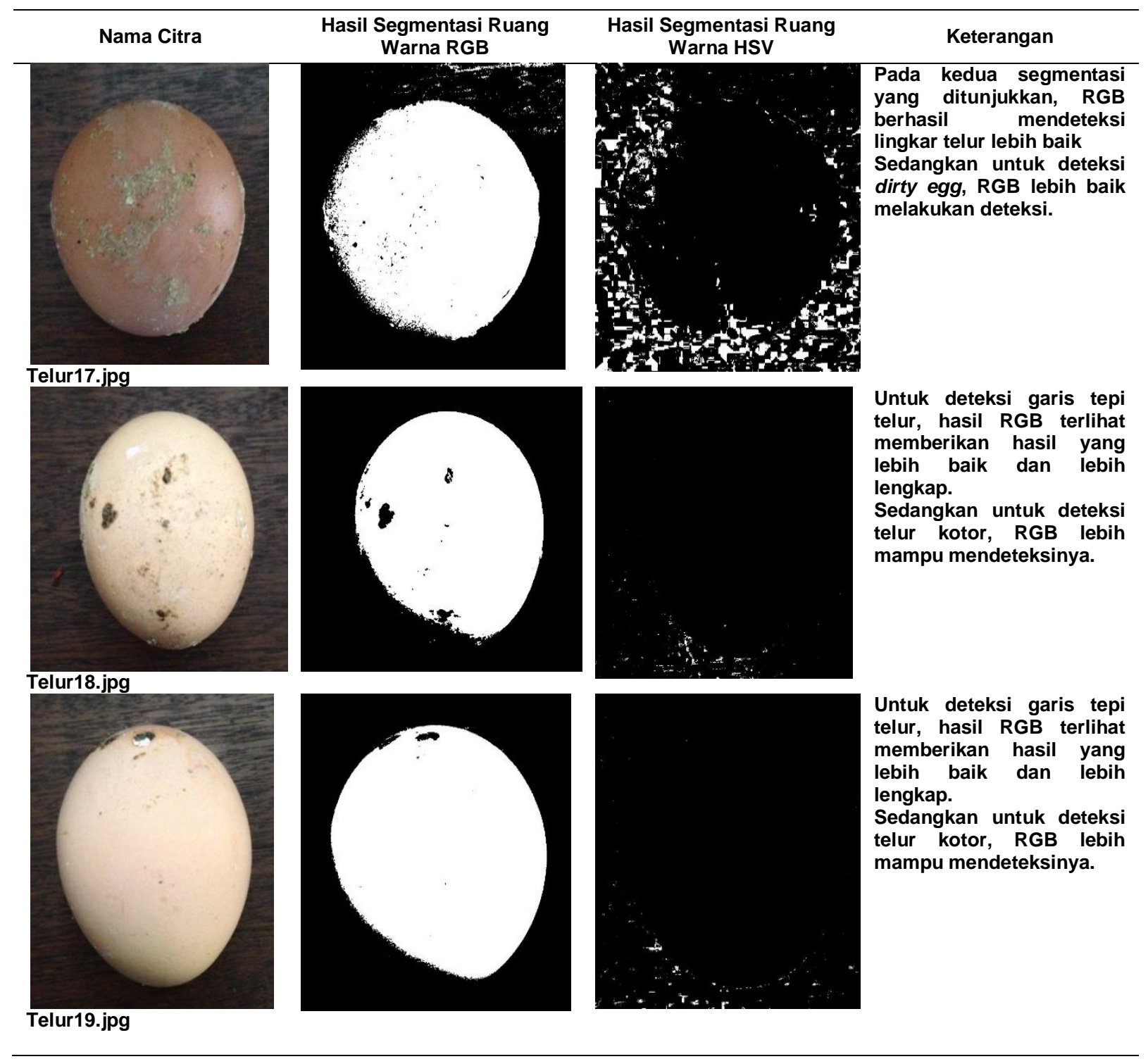

